\title{
scripted
}

Volume 17, Issue 1, January 2020

\section{Book review: Cryptocurrencies in Public and Private Law}

\author{
David Fox and Sarah Green (eds.) \\ Oxford: Oxford University Press, 2019. 323 pages. ISBN 978-0-19-882638-5. \\ $£ 95.00$.
}

Reviewed by Israel Cedillo Lazcano*

(ㄷ) (ㅇ) $\odot$

(C) 2020 Israel Cedillo Lazcano

Licensed under a Creative Commons Attribution-NonCommercial-

NoDerivatives 4.0 International (CC BY-NC-ND 4.0) license

DOI: $10.2966 /$ scrip.170120.171

* PhD candidate, University of Edinburgh, Edinburgh, Scotland, I.C.Lazcano@ed.ac.uk. 
The emergence of "cryptoassets" has inspired a voluminous body of scholarship produced by authors from different backgrounds and levels of understanding. Within this universe, when one looks for works on the regulation and legal nature of these innovations, one will find that most of these documents can be organized into two categories: 1) those that try to offer a single unified legal theory of Distributed Ledger Technology (DLT), and 2) those that are focused on money and free banking paradigms. Both categories structured around the ideas found in the whitepaper published by Satoshi Nakamoto.

In the middle of this production, David Fox and Sarah Green have put together a rather interesting work that offers not only some names like Charles Proctor and Benjamin Geva who are well-known among the scholars that work on the legal nature of money, but also several contributions that cover issues that have been left in a marginal position in the literature. Accordingly, the book offers 11 chapters that cover the description of Bitcoin and its protocol, the debates relating to the role of DLT innovations in our understanding of money and banking, the issues related to the conflict of laws, and the conception of these assets as property, among others. All of them are analysed under the light of different legal traditions in America, Europe and Asia.

To introduce this work, Sarah Green presents a brief description of the technology applicable to the protocols based on Proof-of-Work (PoW) like Bitcoin, and introduces the contributions of the rest of her co-authors. From that point, we can see how Green develops, in the following chapter (Chapter 2), her main contribution taking as a starting point the definition provided by Darling J in Moss $v$ Hancock, ${ }^{1}$ which is considered one of the best definitions of money that

1 Darling J defined money as "that which passes freely from hand to hand throughout the community in final discharge of debts and full payment for commodities, being accepted equally without reference to the character or credit of the person who offers it and without the intention of the person who receives it to consume it." See [1899], 2 Q.B. 111 (UK) at 116. 
go beyond the descriptions of its three main functions (money as medium of exchange, unit of account and store of value). This definition is useful to understand the arguments developed further by Kelvin FK Low and Wu YingChieh in Chapter 8, and by Benjamin Geva and Dorit Geva in Chapter 11.

The function of payment found in Moss $v$ Hancock is highlighted through the private law concept of money, by which she separates accurately the terms "money" and "currency." From that point, she argues, building on the analysis of cases, such as, O'Dea $v$ Merchants Trade-Expansion Group Ltd and Davies v Customs and Excise Commissioners, that "there is no good reason for private law to distinguish between fiat and virtual currencies."

However, her argument does not reach its full potential given that it is heavily focused on Bitcoin and on the on-chain interactions, expressing following a traditional Arrow-Debreu model - that "there is not only no requirement for third-party intervention but also there is no room for it." If we analyse the evolution of this market, as evidenced by projects like Facebook LIBRA and the analysis developed in Chapter 9, we can infer that this argument is not entirely true.

From this point, the book can be divided in two main parts. The first one constituted around the analysis of "cryptoassets" as money and/or integral elements of our payment systems, and the second one focused on the analysis of "cryptoassets" as property. This division is not reflected in the order of the chapters. For instance, the questions relating to the nature of "cryptoassets" as money are found in Chapters 2, 3, 4, 9 and 11, with two transitional chapters (5 and 10) that guide us towards the analyses on these innovations as property under different legal traditions (Chapters 6, 7 and 8). 
Following this observation, the contribution developed by Geva and Geva in Chapter 11 - which I consider could be inserted as Chapter 3 to act as the cornerstone of the first part of the book - takes the analysis of communitarian monies to digital environments. Building upon the difference between "money" and "currency," just as Sarah Green did, the authors present to the reader an excellent socio-legal analysis of money that combine with talent anthropological and legal arguments. Through this exercise, they introduce the principle found in Vick $v$ Howard $^{2}$ related to the concept of legal tender to argue that communitarian monies, foreign currencies and "cryptoassets" are money but they cannot be labelled as "currencies" within a single jurisdiction. From a monetary perspective, this could be the most relevant chapter of the book.

Complementing these contributions, one will find the analysis of Charles Proctor who structures his argument around the State Theory of Money; thus setting the leitmotif for the chapters developed by Andrew Dickinson, Kelvin FK Low and $\mathrm{Wu}$ Ying-Chieh. For this purpose, Proctor opens arguing that "cryptoassets" are not money under a post Westphalian perspective, making an interesting contrast between the basic design of these innovations and its compatibility with the lex monetae. From this point, he puts "cryptoassets" under the light of constitutional elements, and ponders their potential relevance for financial stability and criminal law through cases like US $v$ Murgio. ${ }^{3}$ With this basis, the author concludes that "cryptoassets" are not money, but that they can be considered as species of property or a new asset class, an issue that is partially challenged by Corinne Zellweger-Gutknecht in Chapter 4 .

2 This case presents us a rather interesting principle, which states "that all money is not legal tender, though all legal tender is money." See [1923] 116 S.E. 465 (US), at 214.

3 [2015], 15-cr-00769 AJN (US). 
Zellweger-Gutknecht takes the reader to paths that are more familiar and builds upon a well-developed tracing of the evolution of banknotes. Accordingly, the author shows how the substance and value of money has evolved throughout our financial history. In addition to the nice selection of cases and legislation that she introduces in her work, the inclusion of the transitions materialized between the opinions found in cases like Ford $v$ Hopkins ${ }^{4}$ and Miller $v$ Race, ${ }^{5}$ and Suffel $v$ Bank of England 6 could have added some value to the argument. From this exercise, the author turns her attention to the modes of money creation and their relevance for the creation of sovereign "cryptoassets." Taking as her starting point the now famous "money flower" of Bech and Garratt, Zellweger-Gutknecht offers us a classification of money. This latter based on the underlying asset that backs a monetary manifestation from tangible elements close to the Metallist Theory, to new digital environments that rely on the Chartalist Theory of money, which, according to the author, require a separate set of rules following the traditional elements of general property law. An interesting conclusion, which could have more impact in the context of digitization of commodities. After all, the Chartalist Theory of money relies on faith, not the underlying asset as described by Kiyotaki and Wright. ${ }^{7}$

To close the first part of this work, Christopher Hare makes an analysis of "cryptoassets" under the light of two of the three main monetary functions: money as a store of value and money as a medium of exchange. From an initial point of view, one could be tempted to think that the author is following a rather common path; however, his contribution is original. He takes these functions to

[1701] 1 Salk. 283 (UK).

[1758] 1 Burr. 452 (UK).

[1882] 9 Q.B.D. 555 (UK).

N. Kiyotaki and R. Wright, "On Money as a Medium of Exchange” (1989) 97 Journal of

Political Economy 927-954. 
offer a very useful contrast between the products and services provided by traditional banking and how new technologies, such as, DLT could challenge them, particularly through a new generation of "shadow banks."

After this first part, we can identify the transitional chapters. First, Andrew Dickinson defines the transition from the analyses of "cryptoassets" as money to these innovations as property through the conflict of laws. This analysis is very interesting, probably one of my favourite chapters within this work. The author covers a wide offer of potential conflicts, and even goes beyond Bitcoin including in his analysis projects, such as, Ripple. Something refreshing for the reader that wants to learn about the technology and its Schumpeterian diffusion. Through this chapter, one can find a brief description of potential problems relating to rules of jurisdiction and applicable law in digital environments under different levels of decentralization. Personally, I would have loved a mention regarding the test found in Zippo Manufacturing Company v Zippo Dot Com, INC., ${ }^{8}$ linked to the analysis of the case Car Trim GmbH v Key Safety Systems Srl. ${ }^{9}$ However, independently of this, in general terms, the transition from lex monetae to "cryptoassets" as property under the light of regulations such as Rome I is appropriate given the content of the following chapters.

To close this transition, Anne Fairpo covers the issues related to the taxation of these instruments, making an interesting analysis that goes beyond DLT including other forms of virtual assets like those found in Second Life and World of Warcraft. This exercise is important because, through it, the author makes a clear distinction between those assets whose circulation is restricted to closed environments and those that can be employed in the real economy, the latter of these being of interest for tax authorities. I would have preferred having this

\footnotetext{
[1997] 952 F.Supp. 1119 (UK).

[2010] C-381/08 ECLI (EU).
} 
chapter in the middle of the book as an introduction to the contributions of authors like David Fox. Despite the fact that Fairpo acknowledges that "cryptoassets" could be labelled as "money," she focuses her attention on the analysis of these innovations as property for fiscal purposes.

David Fox opens what I identify as the second part of the book with a deep analysis of these innovations as property, mostly in on-chain contexts through a hypothetical "crypto-coin" designed after Bitcoin. The author faces the question regarding the requirement of some tangible control over a tangible thing to be considered as property, something similar to the question posed by Sir Iain Glidewell ("Is software goods?") in St Albans City and District Council v International Computers Limited. ${ }^{10}$

To face this challenge, Fox argues that his "crypto-coin" is not a simple piece of information and compares it to banknotes and electronic money. He highlights that this asset is fungible; thus, he avoids to follow the line set by Lord Holt who in Ford $v$ Hopkins ${ }^{11}$ stated that "money or cash is not distinguished, but these notes or bills are distinguishable, and cannot be reckoned as cash, and they have distinct marks and numbers on them." However, the author states that this fact does not mean that property and money are opposite legal categories. One can agree partially with him, but the argument needs more refinement, and consider new protocols like "Proof-of-Authority" to show how the technology is evolving to face the issues that Fox is describing. Furthermore, the analysis of "cryptoassets" as property is relevant, but it will depend on the industry that adopts the technology. We can be certain that we do not need a universal theory of "cryptoassets", but different proposals to face different challenges that go from

10 [1996] EWCA Civ J0726-13 (UK).

11 [1701] 1 Salk. 283 (UK), at 284. 
the constitution of new payment systems to the improvement of supply chains could find their cornerstones in this chapter.

Building on the introduction provided by David Fox, Daniel Carr (Chapter 7), Kelvin FK Low and Wu Ying-Chieh (Chapter 8) start acknowledging that independently of the legal system, all of them face the same challenges as regards "cryptoassets". First, Carr opens stating that "property law tends to be quite resistant to attempts at harmonization, let alone plans for unification." Yes, he is right, but that is not applicable to the post-Westphalian monetary arrangements that he tries to cover, which are characterized by network effects and harmonization. Furthermore, he introduces an interesting analysis based on intellectual property, but he states that "cryptoassets" are in the realm of confidentiality, when these instruments are designed to circulate. We have to make a clear distinction between the technology that allow us to encrypt data and the asset that results from the application of DLT to monetary matters. These comments, do not mean that this chapter lacks of quality, but it repeats the discussions introduced by St Albans that certainly are useful for other nonfinancial applications that could rely on DLT.

Low and Ying-Chieh offer us an interesting and refreshing introduction to the legal systems of Japan, China and South Korea, from which they start their analysis. The authors consider, that under the concepts of zaisan, cáichăn and jaesan, "cryptoassets," from an initial point of view, could be considered as property as described by Fox. However, this argument is challenged by the opinion held by the Tokyo District Court in the context of Mt Gox failure, something that allowed the authors to take their analysis to the context of innovations that go beyond Bitcoin like Initial Coin Offerings (ICOs) and Decentralized Autonomous Organizations (DAOs). Personally, I think that the relevance of the second part of the book will be related to the evolution of the 
innovations analysed by Low and Ying-Chieh, and probably this book needed a chapter focused on ICOs and DAOs.

I would have called this book "Cryptoassets" in Public and Private Law to include non-monetary instruments, particularly considering the attention paid to the elements of property and conflict of laws, but in general terms, this book has a very interesting content that could -and probably will- be relevant for further academic and regulatory discussions. The only and big restriction that this book will face is the over-emphasis paid to Bitcoin. This instrument is relevant and has to be mentioned, but the elements analysed and introduced in this book required the analysis of other protocols like "Proof-of-Stake," and "Proof-of-Authority" and projects, such as, Ripple, Ethereum, Corda, among others. Finally, I would have explored cases relating to the nature of software to complement the arguments presented in this work, particularly those that analysed these instruments as property. 